\title{
Libras, Bilinguismo e Educação Bilíngue: 0 Território do Surdo
}

\author{
Libras, bilinguism and bilingual education: the territory \\ of the deaf.
}

\section{Libras, bilinguismo y educación bilingüe: el territorio de los sordos.}

\author{
iD Dayse Garcia Miranda \\ Universidade Federal de Ouro Preto, Mariana, Minas Gerais, Brasil. \\ E-mail: dayse.miranda@ufop.edu.br
}

\begin{abstract}
Resumo: Uma comunidade linguística não se refere apenas às pessoas que habitam determinados territórios. Os princípios que norteiam os Direitos Linguísticos adotam a ideia de que o espaço territorial não se classifica como uma área geográfica, mas sim como um espaço social e funcional imprescindível para o pleno desenvolvimento da língua. Nesse sentido, realizou-se uma pesquisa de caráter bibliográfico (OLIVEIRA, 2003, 2011; GROSJEAN, 2008, 2016; QUADROS, 2019; PLAZA-PUST, 2012; ANN, 2004), predispondo-se a discutir aspectos que sustentam os pressupostos teóricos quanto ao Bilinguismo e à Educação Bilíngue pelas perspectivas da esfera pública e da comunidade surda.
\end{abstract}

Palavras-chave: Bilinguismo. Língua de Sinais. Educação Bilíngue.

\begin{abstract}
A language community is not just about people living in certain territories. The principles guiding Linguistic Rights adopt the idea that the territorial space is not classified as a geographic area, but as an essential social and functional space for the full development of the language. In this sense, bibliographic research was carried out (OLIVEIRA, 2003, 2011; GROSJEAN, 2008, 2016; QUADROS, 2019; PLAZA-PUST, 2012;
\end{abstract}

\footnotetext{
1 Refere-se ao surdo bimodal. Trata-se de recorte de um capítulo de Tese defendida por Miranda, D. G., "A multimodalidade no ensino de língua portuguesa como segunda língua para surdos: análise do uso do livro didático adaptado em Libras". Tese de Doutorado. Posling. CEFET-MG, Belo Horizonte, 2019
} 
ANN, 2004) predisposing the discussion of supportive aspects for the theoretical assumptions and Bilingualism and Bilingual Education from the perspective of the public sphere and also from the considerations of the deaf community.

Keywords: Bilingualism. Sign Language. Bilingual Education.

Resumen: Comunidad lingüística no se trata solo de personas que habitan en ciertos espacios. Los principios que guían los derechos lingüísticos adoptan la idea de que el espacio territorial no está clasificado como un área geográfica, sino como espacio social y funcional esencial para el desarrollo completo del lenguaje. En este sentido, se realizó una investigación bibliográfica (OLIVEIRA, 2003, 2011; GROSJEAN, 2008, 2016; QUADROS, 2019; PLAZA-PUST, 2012; ANN, 2004), que predispuso a discutir aspectos que respalden los presupuestos teóricos sobre el Bilingüismo y la Educación Bilingüe desde una perspectiva de la esfera pública y de las consideraciones de la comunidad sorda.

Palabras clave: Bilingüismo. Lengua de Signos. Educación Bilingue.

Submetido em 24 de julho de 2020.

Aceito em 17 de novembro de 2020.

Publicado em 16 de julho de 2021. 
Libras, Bilinguismo e Educação Bilíngue: O Território do Surdo

Dayse Garcia Miranda

\section{Introdução}

Toda e qualquer discussão quanto à surdez passa pela língua. A língua se configura como um meio em que se definem propostas e projetos voltados para as pessoas surdas, tanto no campo educacional quanto no campo linguístico. A realização do papel social sempre será mediada pela língua (langue e parole), que é parte da realidade dos sujeitos e, concomitante, torna-se formadora da sociedade, "assim, a língua é uma condição necessária para aquele elemento final no processo de desenvolvimento do indivíduo, de um ser humano para uma pessoa que podemos chamar de personalidade" (HALLIDAY, 1979 , p. 25, tradução nossa) $)^{2}$. Tem-se a defesa de que um sistema linguístico, enquanto um sistema de significação, é potencialmente realizado por determinadas escolhas feitas pelo falante. Dessa maneira, a língua de um povo influencia no seu modo de compreender a realidade a partir de sua visão de mundo, por isso, ela é ativa, contribuindo para a criação da realidade e oferecendo significações às experiências e interações humanas.

Desde que a Lei n. 10.436, de 24 de abril de 2002, foi sancionada, a Língua Brasileira de Sinais - Libras é reconhecida como língua usual da comunidade surda. No primeiro artigo da lei está expresso o reconhecimento da Libras:

[...] como meio legal de comunicação e expressão a Língua Brasileira de Sinais - Libras e outros recursos de expressão a ela associados. Parágrafo único. Entende-se como Língua Brasileira de Sinais - Libras a forma de comunicação e expressão, em que o sistema linguístico de natureza visual-motora, com estrutura gramatical própria, constituem um sistema linguístico de transmissão de ideias e fatos, oriundos de comunidades de pessoas surdas do Brasil. (BRASIL, 2002, p. 1).

2 Leia-se no original, em espanhol: Así, la lingua es condición necessaria para ese elemento final en el processo de dasrrollo del individuo, desde un ser humano hasta una persona a la que podemos llamar personalidade. 
Libras, Bilinguismo e Educação Bilíngue: O Território do Surdo

Dayse Garcia Miranda

Uma vez entendido que Libras possui um sistema linguístico, sendo, portanto, uma língua, podemos considera-la como natural3; e desenvolvida entre os seus pares linguísticos, isto é, na comunidade de usuários da Língua de Sinais (doravante LS), uma vez que compartilham de características que lhe atribuem o caráter específico de língua. A LS não descende e não depende das línguas orais, e assim, é oriunda da comunidade de surdos, não tendo territorialidade fixa, acontecendo onde há mais de uma pessoa de identidade surda.

\section{Direito Linguístico e Educacional}

A atenção para a língua como lugar de direito, segundo Oliveira (2011, p. 2), ocorreu no ano de 2008, sendo esta uma conquista das comunidades de falantes das 220 línguas brasileiras, bem como pelos movimentos de reconhecimento da diversidade linguística e cultural no país. A partir desse contexto, o Estado se torna o principal articulador das políticas linguísticas nacionais. Entretanto, Gilvan Oliveira afirma que:

[...] percebem-se mais claramente tanto as limitações ideológicas de muitos funcionários de Estado para esta nova situação, de súbito confrontados com novas demandas que não conseguem processar ou aceitar, como as limitações técnicas para a implementação de políticas da diversidade num país que sempre se concentrou na produção da homogeneidade, incluindo-se aqui o seu sistema universitário: há falta de quadros capacitados em quase todas as frentes das novas políticas linguísticas, em especial no desconhecimento técnico para a implementação de ensino bi - ou plurilíngue [com todos os componentes em que isso implica]. (OLIVEIRA, 2011, p. 2).

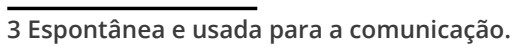


Libras, Bilinguismo e Educação Bilíngue: O Território do Surdo

Dayse Garcia Miranda

Mesmo com os movimentos lutando pelo reconhecimento das diferentes línguas, a imagem construída é de um país monolíngue, admitindo algumas variações dentro de uma só língua. Para o autor, a crença de uma única língua falada no país é decorrente da intervenção do Estado, precisamente com a Reforma Pombalina (século XVIII) ${ }^{4}$, que instituiu a Língua Portuguesa como língua de unidade nacional, conduzindo assim as ações culturais no Brasil.

Com a Constituição de 1988, inicia-se o reconhecimento dos grupos minoritariamente linguísticos. Hoje, essas diferentes línguas são ensinadas em vários espaços educativos e culturais, contudo, são classificadas como línguas estrangeiras (doravante LE) e/ou segunda língua (doravante L2). Destaca-se também que muitas línguas - estrangeiras e Libras - têm sua aquisição no ambiente familiar, e, nesse caso, filhos de surdos e/ou filhos de pais estrangeiros que residem no Brasil. Assim, são pessoas bilíngues que interagem com e em diferentes línguas, em diferentes contextos, dentro do mesmo território.

\begin{abstract}
A publicação no Brasil da Declaração Universal dos Direitos Linguísticos [...] visa introduzir de forma mais sistemática, na comunidade linguística e daqueles que atuam junto das populações falantes de línguas minoritárias, o conceito do direito linguístico, com as implicações que daí decorrem. Visa, sobretudo, tornar-se um instrumento importante na mão daqueles que lutam contra qualquer tipo de discriminação linguística, especialmente os falantes de outras várias línguas brasileiras que não a oficial e hegemônica, o português. (OLIVEIRA, 2003, p. 11)
\end{abstract}

Essa convenção é um fenômeno recente e surge com a intenção de proteger os direitos de grupos linguisticamente minoritários. Os direitos linguísticos fazem parte dos direitos fundamentais, tanto individuais quanto coletivos, e se sustentam nos princípios universais da dignidade dos seres humanos e da igualdade formal

4 Essa reforma exigia um forte controle do Estado e eficiente funcionamento da máquina administrativa. [...] a substituição da língua geral pela língua portuguesa e punição contra discriminações. 
Libras, Bilinguismo e Educação Bilíngue: O Território do Surdo Dayse Garcia Miranda

de todas as línguas (OLIVEIRA, 2003, p. 51). Salienta-se que, nesse caso, considerando-se a surdez, a LS está no espaço social onde se encontram os usuários dessa língua. A comunidade surda está representada por surdos e não surdos; pelos comunicantes da Libras. O espaço discursivo da Libras está nas escolas bilíngues e não bilíngues, nas associações de surdos, em eventos culturais, nos espaços familiares e junto dos amigos de sujeitos surdos. Saliento que, onde estiver mais de uma pessoa surda, naquele ambiente, a LS $^{5}$ e os modos visuais ${ }^{6}$ de comunicação circulam.

Tratando-se de políticas públicas, Oliveira (2011, p. 1) justifica que as políticas linguísticas direcionam decisões referentes às relações entre as línguas e a sociedade - em que língua o Estado funcionará e se relacionará com os cidadãos; em qual(ais) língua(s) a educação e os serviços culturais serão oferecidos; que variedade de língua será usada; se as outras línguas faladas pelos cidadãos serão reprimidas, reconhecidas ou promovidas. Dessa forma, as políticas linguísticas podem ser consideradas como mecanismos para manutenção dos direitos linguísticos, com o propósito de que todos tenham o conhecimento da língua oficial e também das línguas minoritárias e/ou dos dialetos locais. O papel das políticas públicas é procurar desenvolver ações que permitam a convivência da Língua Oficial ${ }^{7}$ com as línguas faladas pelas minorias linguísticas:

[...] conceitua-se Política Linguística como um conjunto de determinações governamentais sobre a língua, ou línguas, na relação destas com a sociedade, visando ou a alteração ou a manutenção do comportamento linguístico de uma comunidade mediante tomada de posição. O conjunto de determinações inclui instrumentos legais de normatização como leis, decretos e portarias que atuarão nos diversos espaços, primordialmente naqueles em que se dá a convivência de diferentes línguas. (SANTOS, 2012, p. 42)

5 Língua de Sinais.

6 Escrita em português, gestos, uso de imagens.

7 Para o contexto do artigo refere-se à Língua Portuguesa. 
Libras, Bilinguismo e Educação Bilíngue: O Território do Surdo

Dayse Garcia Miranda

Assim, cabe destaque à Libras. A LS está contemplada nos seguintes instrumentos legais, que regem as políticas públicas para a área da surdez: Lei № 10.436 - 24 de abril de $2002^{8}$, Decreto № 5.625 - 22 de dezembro de $2005^{9}$, Decreto № 7.387 - 9 de dezembro de $2010^{10}$, Lei № 13.146 - 6 de julho de $2015^{11}$ e, o mais recente, Decreto № 9.665 - 02 de janeiro de 2019.

Com a criação do Decreto 5.626, que a Língua de Sinais Brasileira passa a ser legitimada e a Educação de Pessoas Surdas se constitui por meio de programas de desenvolvimento educacional com enfoque bilíngue. A partir desta data, os estados e municípios viram-se obrigados a subsidiar nos sistemas de ensino a formação de professores da educação, e suas escolas foram obrigadas a abrir as salas de aulas para alunos surdos e ouvintes. Para garantir a inserção do aluno surdo nas instituições de educação básica e nas de educação superior, as escolas deveriam proporcionar aos alunos surdos os serviços do tradutor e do intérprete de Libras - Língua Portuguesa, em sala de aula e nos outros espaços educacionais. (MIRANDA, 2010, p. 52)

Dessa forma, as políticas linguísticas são diluídas nas ações voltadas para educação e para a inclusão. Recentemente, com o anúncio do Decreto № 9.665/2019, foi implantada no Ministério da Educação e Cultura (MEC) a Diretoria de Políticas de Educação Bilíngue de Surdos que, segundo o Art. 35 desse decreto, tem a competência de:

I - planejar, orientar e coordenar, em parceria com os sistemas de ensino voltados às pessoas surdas, com deficiência auditiva ou surdocegueira, e com as instituições representativas desse público, a implementação de políticas de educação bilíngue, que considerem a Língua de Sinais Brasileira (Libras), como primeira língua, e Língua Portuguesa Escrita, como segunda língua; II - fo-

\footnotetext{
8 Dispõe sobre a Libras e oportuniza outras providências, como o seu reconhecimento como meio de comunicação. 9 Regulamenta a Lei $n^{\circ} 10.436$, que dispõe sobre a Libras, e o art. 18 da Lei $n^{\circ} 10.098$.

10 Institui o Inventário Nacional da Diversidade Linguística e possibilita outras providências.

11 Institui a Lei Brasileira de Inclusão da Pessoa com Deficiência (Estatuto da Pessoa com Deficiência).
} 
mentar a criação de Escolas Bilíngues de Surdos, em todo o território nacional, com oferta de educação integral, em todos os níveis, etapas e modalidades de ensino; III - definir e implementar ações de apoio didático, técnico e financeiro ao ensino bilíngue; IV - promover o desenvolvimento de ações para a formação inicial e continuada de profissionais da educação bilíngue; $\checkmark$ - planejar e executar ações que visem ao fortalecimento dos Centros de Apoio aos surdos dentro das Escolas Bilíngues, para a formação educacional, elaboração de materiais didáticos bilíngues e interação com a família; VI - promover a transversalidade e a intersetorialidade da educação bilíngue, visando a assegurar o pleno desenvolvimento linguístico-cognitivo e a aprendizagem dos estudantes surdos, surdocegos e deficientes auditivos; VII formular e implementar políticas que favoreçam o acesso, a permanência e a aprendizagem nas instituições de ensino bilíngue, por meio da integração com setores de cultura, esporte e arte; VIII - promover o acesso a programas de educação linguística precoce e identificação de bebês surdos, por meio de parcerias com órgãos da área da saúde e da assistência social; IX - participar, junto ao Conselho Nacional de Educação, na elaboração de diretrizes voltadas à educação bilíngue de surdos; e X - promover e favorecer a realização de estudos e pesquisas referentes às experiências com e na educação bilíngue de surdos. (BRASIL, 2019, Art. 35)

Desse modo, na perspectiva educacional bilíngue, alguns avanços importantes devem ser explicitados: (i) institucionalização do ensino da Língua de Sinais no ensino superior; (ii) uso da Libras como língua em circulação nos espaços escolares; (iii) Libras e a Língua Portuguesa passam a ser consideradas como línguas de instrução, utilizadas no desenvolvimento do aluno surdo. Consta no Art. 13 do Decreto de Lei № 5626/2005 que o ensino de português como L2 deve ser incluído como disciplina curricular nos cursos de formação de professores para a educação infantil e para os anos iniciais do ensino fundamental, de nível médio e superior, bem como nos cursos de licenciatura em Letras com habilitação 
Libras, Bilinguismo e Educação Bilíngue: O Território do Surdo

Dayse Garcia Miranda

em Língua Portuguesa. E, no novo Decreto, de N 9.665/2019, está a promoção do desenvolvimento de ações para a formação inicial e continuada de profissionais da educação bilíngue. Dessa forma, a política pública linguística defendida pela comunidade surda contempla a educação de surdos como bilíngue (LS/LP) e orienta que a formação de educadores para práticas pedagógicas adote o ensino da LP como L2.

Ao analisar as diretrizes para o ensino de LP na modalidade escrita e também como segunda língua, identifica-se duas vertentes de pensamento: a do Estado e a da comunidade surda. Interessante notar que o Estado elabora planos de ações que conduzem para a diversidade ${ }^{12}$, e, a comunidade surda, para a diferenciação ${ }^{13}$. O Estado justifica a diferenciação como pautada pela diversidade; assim, as políticas públicas devem ser construídas pelo viés da diversidade. Para a comunidade surda, a diferenciação está pautada pela singularidade da língua e, assim, defende projetos políticos que se orientem pela especificidade da língua de sinais (STURMER; THOMA, 2015, p. 12).

No objetivo de elucidar o que está acima escrito, fazemse apontamentos a partir de documentos mais recentes, que refletem as propostas do Estado e da comunidade surda quanto ao ensino de LP como L2 para surdos. Desse modo, apresentamos os pressupostos defendidos no Plano Nacional de Educação (PNE 2014-2024), Lei No 13.005, de 25 de junho de 2014, que foi elaborado pelo Ministério da Educação, em Brasília, no ano de 2014. Quanto à área da surdez, existem apenas dois subitens, Metas e Estratégias (4.7 e 16.3), que dizem da LS e da LP. Vejamos:

(4.7) garantir a oferta de educação bilíngue, em Língua Brasileira de Sinais (Libras) como primeira língua e na modalidade escrita da língua portuguesa como segunda língua, aos (às) alunos (as) surdos e com deficiência auditiva de zero a dezessete anos, em

12 Múltiplas categorias: diferentes raças, gêneros, etnias, classes sociais, religiões, orientações sexuais, habilidades mentais, habilidades físicas [...] (QUADROS, 2019, p. 136).

13 A diferenciação, para os surdos, trata de considerar sua forma de comunicar; ser considerado pela diferença cultural e linguística e que a sua diferença esteja claramente compreendida na educação. A diferença significa ganhos positivos para a surdez (QUADROS, 2019, p. 137). 
Libras, Bilinguismo e Educação Bilíngue: O Território do Surdo

Dayse Garcia Miranda

escolas e classes bilíngues e em escolas inclusivas, nos termos do art. 22 do Decreto $n^{\circ}$ 5.626, de 22 de dezembro de 2005, e dos arts. 24 e 30 da Convenção sobre os Direitos das Pessoas com Deficiência, bem como a adoção do sistema braile de leitura para cegos e surdos-cegos; [...].

(16.3) expandir programa de composição de acervo de obras didáticas, paradidáticas e de literatura e de dicionários, e programa específico de acesso a bens culturais, incluindo obras e materiais produzidos em libras e em braile, sem prejuízo de outros, a serem disponibilizados para os professores e as professoras da rede pública de educação básica, favorecendo a construção do conhecimento e a valorização da cultura da investigação. (BRASIL, 2014)

Passam-se aos pressupostos defendidos pela comunidade surda, e, para tal, buscam-se, no Relatório do Grupo de Trabalho designado pelas Portarias № 1.060/2013 e № 91/2013, subsídios para a Política Linguística de Educação Bilíngue — Língua Brasileira de Sinais e Língua Portuguesa — - a ser implementada no Brasil. Nesse documento (2014b, p. 11), no item 3.2.1, cujo subtítulo é "Português como Segunda Língua na Educação Linguística de Surdos Brasileiros", estão contempladas metas como (i) o estabelecimento de regras explícitas para solucionar situações de conflito produzidas pelas regras implícitas das línguas (LS/LP); (ii) o planejamento deliberado de ensino de línguas para o desempenho satisfatório e (iii) o planejamento para o ensino e para a aprendizagem de línguas, visando influenciar o comportamento do outro no que diz respeito à aquisição, à estrutura e à sistematização funcional dos códigos das línguas em situação de contato. Não se localizaram documentos que confirmem a implementação dessas propostas nos estados brasileiros.

Nesse relatório ${ }^{14}$ são definidas ações para a efetivação de uma política pública bilíngue para os surdos. Transcrevo-as a seguir:

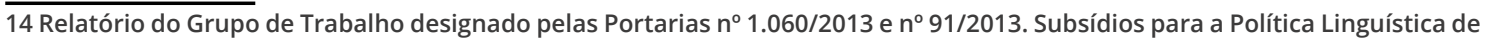
Educação Bilíngue - Língua Brasileira de Sinais e Língua Portuguesa, 2014, p. 12. 
Libras, Bilinguismo e Educação Bilíngue: O Território do Surdo

Dayse Garcia Miranda

Fortalecer o ensino da Libras científica e técnica, com vistas a prover essa Língua de conhecimentos avançados que possibilitem o desempenho de competências e habilidades no plano nacional. Criar condições reais para o avanço da pesquisa contrastiva ${ }^{15}$ Libras (L1) - Português escrito (L2) e Português escrito (L2) - Libras (L1), com base em dados científicos e empíricos em vista da elaboração da Gramática Contrastiva Padrão do Português Escrito por Surdos, que sirva de diretriz e parâmetro para a produção escrita dos surdos. Proporcionar condições de intercâmbio "Língua de Sinais sem Fronteira", de modo a possibilitar que os estudantes surdos brasileiros desenvolvam a competência comunicativa em Línguas de Sinais Estrangeiras e, assim, ampliem os conceitos de línguas em contato na imersão e fora dela (no estrangeiro). Criar cursos de formação de Formadores em Português L2, que contemplem abordagens, métodos e técnicas que favoreçam o ensino contrastivo do português para os falantes de Libras. Nenhum método deverá ser assimilador em favor da língua majoritária nacional. (BRASIL, 2014, p. 12)

Verifica-se que, tanto nos pressupostos do Estado quanto da comunidade surda, a LP, para os surdos bimodais, é considerada segunda língua, e o ensino desta deve se efetivar em ambientes bilíngues. Assim, constata-se a necessidade de se reservar um espaço nessa exposição para refletir quanto ao bilinguismo e à educação bilíngue.

\section{Bilinguismo}

Geralmente, o termo bilinguismo é compreendido como o aprendizado e uso de duas línguas de prestígio. Trata-se de uma condição humana de operar em duas ou mais línguas diferentes. O aprendizado dessas línguas pode ser uma escolha, ou porque o indivíduo se encontra em contextos sociais em que necessite interagir com diferentes línguas no seu dia a dia, sendo assim,

15 Ao fazer a análise explícita entre as duas línguas, estamos utilizando a linguística contrastiva, ou seja, estamos comparando as semelhanças e diferenças entre as línguas em seus diferentes níveis de análise. 
Libras, Bilinguismo e Educação Bilíngue: O Território do Surdo

Dayse Garcia Miranda

trata-se de um fenômeno mundial, pois, a cada dia, mais pessoas se tornam bilíngues.

Jean Ann (2004, p. 41) busca em Grosjean (1982) a definição para o bilinguismo como o "uso regular de mais de um idioma", presente em todos os países, em todas as faixas etárias e classes sociais. Para Grosjean (2016, p. 2), no caso da surdez, o bilinguismo implica no uso da LS pela comunidade surda e da língua oral (LO) pela maioria dos ouvintes. Segundo o autor, cada criança surda pode apresentar diferentes domínios das línguas: algumas crianças podem ter maior desenvoltura na LS; em outras, a LO predomina e, ainda, pode-se observar o equilíbrio no uso das duas línguas (GROSJEAN, 2016). A diferenciação, quanto ao uso de uma das línguas, pode ser justificada pelos diferentes níveis de perdas auditivas e pela complexidade no contato entre as línguas, sendo estas de diferentes modalidades - LS no modo visuoespacial e a LO no modo oral-auditivo. Podemos encontrar diferentes tipos de bilinguismo nas crianças surdas, sendo assim, usarão ambas as línguas nos diversos contextos, tanto no universo surdo quanto no universo ouvinte.

Para a criança surda bilíngue, comumente a LO é adquirida na modalidade escrita. Em alguns casos, na modalidade oral, mas sempre como L2. A LS deve ser adquirida como L1, sendo esta considerada o único meio de comunicação que a criança surda deve usar para desenvolver suas capacidades cognitivas, adquirir conhecimentos, comunicar-se plenamente e compreender o mundo que a cerca. No contexto do surdo, os pressupostos bilíngues são distintos de outros bilíngues por abrangerem o uso de línguas de diferentes modalidades (língua visuoespacial e língua oral-auditiva). O bilinguismo dos surdos é nomeado bilinguismo bimodal e/ou intermodal (QUADROS, 2019. p. 147).

O bilinguismo bimodal é distinto do bilinguismo unimodal, porque os aspectos relacionados à configuração das línguas são expressos por diferentes articuladores (visão/oral), o que permite a simultaneidade no uso. Os bilíngues unimodais não podem produzir fisicamente duas palavras ou frases ao mesmo tempo, 
Libras, Bilinguismo e Educação Bilíngue: O Território do Surdo

Dayse Garcia Miranda

pois as línguas envolvidas são expressas pelo mesmo articulador (voz). Assim, permitem apenas a sequencialidade.

Os bilíngues bimodais podem demonstrar, na interação conversacional, interferência de uma língua sobre a outra. Assim, segundo Quadros et al. (2013, p. 387), os bilíngues bimodais, ao se comunicarem, podem produzir ambas as línguas simultaneamente, em processos assim nomeados: (i) code-blending, sobreposição das línguas; (ii) code-switching, alternância das línguas envolvidas e, por fim, (iii) code-mixed, mistura das línguas. Devido a essa especificidade, os bilíngues bimodais podem usar conhecimentos gramaticais e lexicais das duas línguas, de forma combinada ou separadamente, orientados pelo contexto que aplicam à linguagem. Parece que há uma tendência a escolher uma das línguas para dirigir a produção linguística mesmo na sobreposição, o uso simultâneo das línguas (QUADROS, 2019, p. 149).

Os bilíngues bimodais adquirem e usam suas línguas com diferentes propósitos, em diferentes situações de vida e com diferentes pessoas. Isso acontece precisamente porque as necessidades e usos das línguas são normalmente muito diferentes e os bilíngues raramente desenvolvem a mesma fluência nas duas línguas (GROSJEAN, 2008, p. 164).

Raramente encontram-se bilíngues com competência nativa em duas línguas. Alguns podem ter alta competência em ambas as línguas na modalidade oral e/ou escrita; outros, melhor desempenho na compreensão e/ou na habilidade oral. Assim, antes de identificar o bilíngue, precisa-se identificar o contexto em que se manifesta esse bilinguismo e quais aspectos relevantes àquele contexto devem ser levados em conta para a identificação do indivíduo bilíngue (SALGADO, 2008, p. 25).

Para Jean Ann (2004, p. 42), o conhecimento da língua não nativa é muito imprevisível entre as pessoas. Explica que, enquanto falantes nativos da mesma língua, alcançam mais ou menos o mesmo lugar, isto é, o mesmo nível de proficiência dessa língua, as coisas se tornam muito menos previsíveis com os indivíduos que 
Libras, Bilinguismo e Educação Bilíngue: O Território do Surdo

Dayse Garcia Miranda

aprendem segundas línguas. A aquisição da L2 de um indivíduo pode se desenvolver em diferentes níveis, pois estão incluídos os fatores mais diversos, tais como idade, razões para aprender segunda língua, tipo de formação na segunda língua, motivação para aprender a L2, função que a L2 desempenhará na vida e razões sociolinguísticas para preservar pedaços da L1 na produção da segunda. Assim, o bilinguismo produz tipos extremamente diversos da língua[gem], seja para indivíduos surdos, seja para ouvintes. No caso dos surdos, as coisas são, talvez, ainda mais complexas.

Sendo assim, o acesso dos surdos às duas línguas torna-se mais complexo, sendo determinado por dois fatores não usuais no caso de outras minorias linguísticas: (i) o estatuto desigual das línguas no nível da transmissão pais-crianças, já que se estima que mais de $90 \%$ dos surdos sejam filhos de pessoas ouvintes; (ii) o acesso desigual às línguas, pois não há acesso ao input auditivo ou esse é limitado". (SILVA, 2017a, p. 129)

No caso da surdez, Jean Ann (2004, p. 42) ressalta que, mesmo quando a língua de sinais está no ambiente social, seu status como língua real pode ser questionado, não encorajado ou mesmo não permitido em escolas para o surdo ou com surdos. As LSs e as LOs raramente estão em paridade, por isso privilegiam a LO, a língua majoritária. Dessa forma, reafirma-se que muitos surdos que usam a LS e conhecem uma LO podem não ser considerados bilíngues pelos ouvintes em sua volta. Outra questão que nos chama à reflexão está no conforto do uso das línguas envolvidas (LP/LS), o bilinguismo equilibrado/balanceado: "Pessoas bilíngues que manifestam as suas línguas igualmente porque ou adquirem uma língua mais completamente que a outra, ou porque usam uma língua mais frequentemente que as suas outras que, certamente, foram adquiridas em graus variados" (SALGADO, 2008, p. 24). Segundo Ann (2004, p. 43), esse tipo de bilinguismo não é comum para os usuários de línguas orais. Logo, espera-se que não haja 
Libras, Bilinguismo e Educação Bilíngue: O Território do Surdo

Dayse Garcia Miranda

equilíbrio entre o uso da LS e a LP nas pessoas surdas. A maioria dos bilíngues tem uma língua dominante e um domínio não dominante de outro idioma.

\begin{abstract}
Eles funcionam de forma variada durante suas vidas. Assim como uma pessoa fluente em chinês, mandarim, que sabe o suficiente de inglês para trabalhar em um emprego, mas não pode ler artigos acadêmicos ou discutir assuntos esotéricos em inglês, seria considerado bilíngue, seria uma pessoa surda fluente em língua de sinais que também sabe ler e escrever a língua oral, mas não sabe pronunciar essa língua (ANN, 2004, p. 42, tradução nossa) $)^{16}$.
\end{abstract}

Quadros (2019, p. 148), a partir de Grosjean (1982), aponta quais atitudes negativas e positivas em relação aos diferentes níveis de domínio nas línguas interferem no desempenho linguístico dos falantes e sinalizantes. Atitudes e valores sobre a língua afetam seus usuários, sendo difícil separar a língua de seus utentes. Portanto, a autora discorre sobre a LS ser, geralmente, usada entre surdo-surdo e surdo-ouvinte (que saiba a LS) para conversar, assistir palestras e aulas, logo, ela é a língua de interação. A LP, no caso da surdez, é usada nos espaços acadêmicos, nas redes sociais, para leitura e escrita. Os domínios variam e podem evidenciar língua dominante e não dominante. Contudo, Grosjean (2008, p. 175) enfatiza que ser bilíngue exige do falante esforço cognitivo processual para operar nas línguas. O autor afirma existirem várias pesquisas significativas sobre o bilinguismo e o indivíduo bilíngue, e ressalta que a visão do bilinguismo, segundo o padrão monolíngue, tem perdido espaço nas investigações. Hoje, as pesquisas concentram-se em questões que dizem das estruturas e organizações das diferentes línguas, dos processos operacionais envolvidos na percepção e da produção e memorização; entre mudanças de códigos; empréstimos e interferências; organização

\footnotetext{
16 Leia-se, no original, em inglês: They function variously in both during their lives. Just as a hearing person fluent in Mandarin Chinese who knew enough English to work at a job, but could not read academic articles or discuss esoteric subjects in English, would be considered bilingual, so would a deaf person fluent in a natural sign language who also knew how to read and write a spoken language but did not speak it.
} 
Libras, Bilinguismo e Educação Bilíngue: O Território do Surdo

Dayse Garcia Miranda

do cérebro do bilíngue; e, finalmente, a psicologia da pessoa bilíngue e bicultural.

Para Plaza-Pust (2012, p. 950), devido à diversidade de fatores que determinam a aquisição e uso da LS e da LO em surdos, o bilinguismo bimodal oferece um rico campo de pesquisa sobre a complexa inter-relação entre a psicolinguística e a sociolinguística, e os fatores que moldam os resultados do contato das línguas. Assim, para a perspectiva da surdez, cabe continuar a discussão quanto ao bilinguismo, configurando-se a partir da educação dos surdos, apresentando suas especificidades e elementos que contribuam para que o aluno surdo tenha garantido o acesso e o aprendizado das duas línguas que constituem sua esfera bilíngue bimodal.

\section{Educação bilingue}

A revista Exame publicou, em 17 de abril de 2017, o artigo Educação bilíngue cresce em todas as regiões do Brasil. Essa notícia informa que, no Brasil, não existe uma regulamentação que defina exatamente o que é uma escola bilíngue ${ }^{17}$. A reportagem evidencia também a tendência crescente pela educação bilíngue que busque atender a uma demanda mercadológica, embora demonstre que o enfoque está em línguas estrangeiras orais, como inglês e espanhol. Essasleiturasnosfazem reafirmar que estáno Estado a promoção de condições de paridade e reconhecimento da diversidade linguística brasileira, como também a responsabilidade da configuração das diretrizes que orientem para a educação bilíngue. Adentrando na surdez, a educação tem um papel proeminente em relação ao bilinguismo bimodal. A educação bilíngue envolve o uso de duas línguas: Libras e LP. Esta deve contemplar a perspectiva social, linguística e cultural da surdez e estar definida por documentos legais, por meio de políticas públicas (QUADROS, 2019, p. 150).

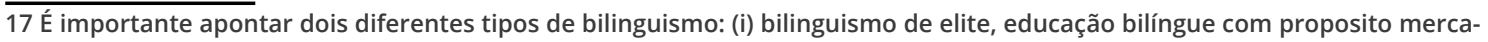
dológico e (ii) bilinguismo de minoria, educação bilíngue de grupos minoritários. 
O bilinguismo é o ponto de partida para a educação bilíngue. No entanto, destaca-se que o desenvolvimento bilíngue em crianças surdas é determinado por dois fatores: (i) o status desigual das línguas envolvidas (LS/LP), o nível da transmissão entre pais e filhos (mais de $90 \%$ dos surdos nascem de pais ouvintes); e (ii) a acessibilidade desigual dos surdos às línguas (sem input auditivo, limite no acesso). Como premissa para a educação bilíngue, é importante considerar, também, a aquisição e o uso das duas línguas, a interação dessas línguas e qual é o papel da LS na alfabetização da criança surda (PLAZA-PUST, 2012, p. 950).

Pode-se afirmar que a educação bilíngue reconhece as diferenças entre as línguas (LS/LP), valida a surdez como experiência visual e, por fim, o mais importante, legitima a LS como primeira língua da criança surda. Para Silva (2017a, p. 129), a aquisição da LS na infância, está diretamente ligada ao contato com essa língua. Para isso, a criança surda dependerá da participação em projetos ou programas que visem a garantir o seu desenvolvimento linguístico e cognitivo em idade pré-escolar.

\begin{abstract}
A questão das línguas está implicada na educação bilíngue para os surdos. A língua de sinais, enquanto primeira língua e língua de interação dos surdos, impacta diretamente as formas de organizar a educação bilíngue e os espaços educacionais. O fato de a língua portuguesa não ser adquirida de forma espontânea pelos surdos também apresenta implicações no contexto escolar. (QUADROS, 2019, p. 151)
\end{abstract}

Para Plaza-Pust (2012, p. 958), existem dois princípios fundamentais da educação surda bilíngue: (i) a língua de sinais é a principal linguagem das crianças surdas, em termos de acessibilidade e desenvolvimento; (ii) a língua de sinais é a primeira língua. A operacionalidade desses princípios vai variar do contexto educacional e dos projetos que articulam intervenções precoces, estando centrada no desenvolvimento da LS como pré-requisito para a educação de surdos. No entanto, esse requisito geralmente 
Libras, Bilinguismo e Educação Bilíngue: O Território do Surdo Dayse Garcia Miranda

não está definido, e as crianças entram nas escolas de educação bilíngue e/ou inclusiva com pouca ou nenhuma competência na LS. Isso ocorre pelo fato de muitas crianças surdas não aprenderem a língua em casa.

Além disso, muitas vezes essas crianças não têm a oportunidade de desenvolver sua competência bilíngue, ou seja, a consciência de sua própria condição bilíngue e o conhecimento sobre contrastes entre suas duas linguagens (consciência metalinguística). A LS, língua minoritária, ocupa pouco espaço nas discussões políticas, e, assim, existe um distanciamento entre o atendimento clínico e educacional, afetando todo o processo de condução assertiva dessa criança.

Faço um recorte aqui para apontar que, até a presente data, mesmo com alguns avanços políticos, o olhar clínico ${ }^{18}$ para a surdez se mantém. Nota-se uma elevação na protetização das crianças surdas, isto é, um aumento excessivo de cirurgias de implante coclear $^{19}$. Para Plaza-Pust (2012, p. 960), à medida que mais e mais crianças surdas recebem o implante coclear, afastam-se os dispositivos que objetivam a educação bilíngue, pois tal implante reconfigura a relação ao uso da língua (sinais/oral), e, dessa forma, impõe-se a redefinição quanto às capacidades e necessidades linguísticas das crianças surdas. Conjuntamente, exalta-se a LO e organiza-se a relação da sociedade a partir da fala e da escrita. A LS volta ao lugar de subordinação à LP oral.

Sob a perspectiva da educação, as crianças surdas podem frequentar aulas em uma escola regular com proposta inclusiva, apoiada pelo intérprete de Libras e pelo atendimento na sala AEE (Atendimento Educacional Especializado). Nesse tipo de educação, é comum levar em consideração a competência em LS das crianças, embora o ensino desta não esteja no mesmo padrão da LP. Em escolas específicas para surdos, a LS circula com facilidade, embora se observe que a LP orienta as práticas didáticas, pois a maioria

$18 \mathrm{Em}$ relação ao bilinguismo dos surdos, pode-se dizer que esse escrutínio dos efeitos negativos é ainda reforçado por uma visão clínica da surdez que vê a LS como um instrumento "compensador" e não como sistema linguístico legítimo (SILVA, 2017, p. 130).

19 o implante coclear (IC) é um dispositivo eletrônico, parcialmente implantado, que visa proporcionar aos seus usuários sensação auditiva próxima ao fisiológico. 
Libras, Bilinguismo e Educação Bilíngue: O Território do Surdo

Dayse Garcia Miranda

dos professores a têm como língua nativa. Além disso, tanto na escola bilíngue quanto na inclusiva, a maioria das crianças surdas têm contato com sua própria língua a partir de modelos adultos que, na sua maioria, não são usuários nativos dessa língua.

A premissa da educação bilíngue para surdos está na Libras como a L1, que deve ser a língua central do ambiente escolar no qual será usada para interação e ensino. A LP, segunda língua, também deve estar presente. $\mathrm{O}$ aprendizado da L2 exigirá mais esforço dos alunos surdos, pois demanda uma instrução formal e se concentra no âmbito da leitura e escrita. A LP tem que estar associada ao uso real na vida do aluno surdo. No espaço escolar bilíngue, as línguas se diferem e complementam. A LS e a LP precisam compartilhar os espaços da escola de igual para igual.

Nesse sentido, os objetivos da educação bilíngue são:

[...] legitimar a experiência visual; (b) assegurar o desenvolvimento socioemocional íntegro das crianças surdas a partir da identificação com surdos adultos (encontro surdo-surdo); (c) criar um ambiente linguístico-social apropriado às formas particulares de processamento cognitivo e linguístico das crianças surdas; (d) garantir as possibilidades para que as crianças surdas construam uma teoria de mundo; (e) oportunizar o acesso à informação curricular e cultural. (QUADROS, 2019, p. 156)

De acordo com Plaza-Pust (2012, p. 960), há um consenso entre os profissionais que trabalham na educação de surdos sobre o fato de que não existe alinhamento da LS usada em casa e na escola. Muitas crianças surdas não frequentam escolas bilíngues, pois não há na região e/ou cidade onde moram o que compromete sua condição bilíngue. Contudo, identifica-se a concordância entre os profissionais quanto à necessidade de haver maior planejamento para a educação bilíngue, envolvendo todos os interessados (direção, professores, pais, representantes surdos e políticos), com o objetivo de alinhar as diferentes medidas que precisam ser tomadas, tais como: (i) formação adequada de professores; 
Libras, Bilinguismo e Educação Bilíngue: O Território do Surdo

Dayse Garcia Miranda

(ii) desenvolvimento de materiais de ensino especificamente concebidos para o bilinguismo de sinais, (iii) foco nos aspectos que distinguem o bilinguismo bimodal de outras formas de bilinguismo, dentre outras.

A educação bilíngue para as crianças surdas está em passos lentos no Brasil, e nota-se que os argumentos dos representantes governamentais se justificam pela extensão territorial do país. Entretanto, defendem como proposta educativa o direito das crianças surdas terem contato com sua língua e com sua cultura. Esse direito só será de fato assegurado caso a LS não seja tratada como um mero acessório na educação dessas crianças, mas como instrumento e condição de sua aprendizagem.

Ressalta-se que as propostas públicas educativas para os alunos deficientes estão construídas em acordo com a Nota Técnica № 05/2011 e com o Plano Nacional de Educação (BRASIL, 2014a), que orientam para a educação inclusiva, implementada com base nos princípios da Convenção dos Direitos das Pessoas com Deficiência, e que "preconiza que a garantia do direito à educação se efetiva por meio do acesso à educação inclusiva em todos os níveis" (BRASIL, 2011, p. 1), "assegura um sistema educacional inclusivo em todos os níveis" (BRASIL, 2014a, p. 1) e "estabelece a educação inclusiva como direito inalienável das pessoas com deficiência" (BRASIL, 2014a, p. 23). Para a implementação de uma educação bilíngue, quanto à criação de ambientes linguísticos, preconizam-se, no Decreto № 5626:

I - Escola e classes de educação bilíngue, abertas a alunos surdos e ouvintes, com professores bilíngues na educação infantil e nos anos iniciais do ensino fundamental;

II - Escolas bilíngues ou escolas comuns do ensino regular, abertas aos alunos surdos e ouvintes, para os anos finais do ensino fundamental, ensino médio ou educação profissional, com docentes das diferentes áreas do conhecimento cientes da singularidade linguística dos alunos surdos, bem como com a presença de tradutor/ intérprete de Libras e Língua Portuguesa. (BRASIL, 2005, Art. 22) 
Libras, Bilinguismo e Educação Bilíngue: O Território do Surdo

Dayse Garcia Miranda

Continua o Decreto 5626/2005:

Art. 16. A modalidade oral da Língua Portuguesa, na educação básica, deve ser ofertada aos alunos surdos ou com deficiência auditiva, preferencialmente em turno distinto ao da escolarização, por meio de ações integradas entre as áreas da saúde e da educação, resguardado o direito de opção da família ou do próprio aluno por essa modalidade. (BRASIL, 2005, Art. 16)

De acordo com as diretrizes da Nota Técnica 05/2011 do MEC:

[...] o AEE deve integrar o projeto político pedagógico da escola, envolver a participação da família e ser realizado em articulação com as demais políticas públicas. Para a oferta deste atendimento, deve ser disponibilizado: professor para Atendimento Educacional Especializado, profissional para atuar em atividades de apoio, tradutor e intérprete da Língua Brasileira de Sinais, guia intérprete, entre outros. A oferta do AEE é fundamental para a efetivação da proposta de educação bilíngue estabelecida no Decreto $n^{\circ} 5626 / 2005$, que regulamenta Lei $n^{\circ}$. 10.436/2002. De acordo com este Decreto, a educação bilíngue para estudantes com surdez caracteriza-se pelo ensino ministrado por meio da Língua Portuguesa e da Libras, devendo ser disponibilizados os serviços de tradutor/intérprete e o ensino da Libras. (BRASIL, 2011, p. 105-106)

Lê-se na Nota Técnica 05/2011 do MEC que “a educação bilíngue para estudantes com surdez, não está, pois, condicionada a espaços organizados, unicamente, com base na condição de surdez"(BRASIL, 2011, p. 106). Como contraponto ao posicionamento do Estado, a comunidade surda, a partir do Relatório do Grupo de Trabalho, designado pelas Portarias № 1.060/2013 e № 91/2013, contendo subsídios para a Política Linguística de Educação Bilíngue - Língua Brasileira de Sinais e Língua Portuguesa (BRASIL, 2014b), apoia-se 
Libras, Bilinguismo e Educação Bilíngue: O Território do Surdo

Dayse Garcia Miranda

no Art. 24 da Declaração Universal dos Direitos Linguísticos para enfatizar que:

Todas as comunidades linguísticas têm direito a decidir qual deve ser o grau de presença da sua língua, como língua veicular e como objeto de estudo, em todos os níveis de ensino no interior do seu território: pré-escolar, primário, secundário, técnico e profissional, universitário e formação de adultos. (OLIVEIRA, 2003, p. 33)

Em 2013, a FENEIS20 elabora a Nota Oficial: educação de surdos na meta 4 do PNE, que caracteriza escolas bilíngues da seguinte forma:

As escolas bilíngues são aquelas onde a língua de instrução é a Libras e a Língua Portuguesa é ensinada como segunda língua, após a aquisição da primeira língua; essas escolas se instalam em espaços arquitetônicos próprios e nelas devem atuar professores bilíngues, sem mediação de intérpretes na relação professor - aluno e sem a utilização do português sinalizado. As escolas bilíngues de surdos devem oferecer educação em tempo integral. Os municípios que não comportem escolas bilíngues de surdos devem garantir educação bilíngue em classes bilíngues nas escolas comuns (que não são escolas bilíngues de surdos). (FENEIS, 2013, p. 3).

Assim, Fernandes (2003, p. 56) ressalta que a expressão educação bilíngue é usada pelos educadores, porém os princípios que regem esta concepção são confundidos com a mera inclusão da LS nas salas de aulas e com a tradução dos conteúdos pedagógicos para a Libras.

Desta forma, com o exposto, é possível caracterizar onde se localizam os alunos surdos nas redes de ensino público ou privado. A configuração dos espaços educacionais são: (i) escolas bilíngues,

20 FENEIS - Federação Nacional de Educação e Integração de Surdos/RJ. 
Libras, Bilinguismo e Educação Bilíngue: O Território do Surdo

Dayse Garcia Miranda

onde a língua de instrução é a Libras e a LP é ensinada como L2, mediada pela língua de instrução. Essas escolas se instalam em espaços arquitetônicos próprios e nelas atuam professores bilíngues, sem mediação por intérpretes e sem a utilização do português sinalizado. Os alunos não precisam estudar no contraturno em classes de AEE; (ii) classes bilíngues, que podem ocorrer nos municípios em que a quantidade de surdos não justifica a criação de uma escola bilíngue específica e podem existir na mesma edificação de uma escola inclusiva; (iii) escolas inclusivas, em que o português oral é a língua de instrução, algumas vezes mediada por intérpretes, e o aluno surdo tem que estudar dois períodos, participando do AEE no contraturno. Os alunos surdos que frequentam classes inclusivas têm o apoio de um intérprete educacional e professor do AEE.

\section{Considerações Finais}

De fato, existe a consciência, tanto do Estado quanto da comunidade surda, de que a Libras tem seu lugar garantido na escola, na sala de aula, nos materiais didáticos, nos espaços educacionais, como também se sabe da importância da aquisição da Língua Portuguesa. No entanto, ainda não está claro para muitos dos profissionais da educação que bilinguismo não é apenas a aquisição de duas línguas no espaço escolar (FERNANDES, 2003, p. 56). Desta maneira, a entrada da Língua de Sinais efetiva-se, circula, mas não se observa nos educadores o entendimento de práticas bilíngues.

A questão da educação de surdos ainda é um problema que se encontra em plena discussão. Pouquíssimas são as escolas dedicadas à oferta de um ensino bilíngue para surdos, e atendem apenas a uma minoria de surdos nesse país. A política educacional que contempla uma educação bilíngue apregoa o respeito e o desenvolvimento dos sujeitos surdos a partir da sua língua, contudo, a realidade da inclusão do aluno com surdez na sala de 
Libras, Bilinguismo e Educação Bilíngue: O Território do Surdo Dayse Garcia Miranda

aula e a efetiva contratação de ILS, sala de AEE, são os panoramas mais próximos à realidade educacional do surdo brasileiro. Desta forma, enquanto ainda os envolvidos discutem sobre o real cenário e as perspectivas futuras para a educação de surdos, observa-se que a postura adotada nas escolas e pelos educadores necessita de maior direcionamento, uma vez que o que se evidencia são desconhecimentos no que diz respeito às realidades das comunidades surdas, a falta de preparo dos educadores e a falta de oportunidade de discussão sobre essa prática.

Quanto à educação de surdos, na perspectiva bilíngue, avança-se nas discussões, embora esta área ainda se encontre em fundamentação. Contudo, em cada discussão, os aportes linguísticos e educacionais não podem ser perdidos de vista, uma vez que o território do surdo é feito em sua própria língua - Língua de Sinais!

\section{Referências}

ANN, Jean. Bilingualism and language contact. In: LUCAS, Ceil. The Sociolinguistics of Sign Languages. Cambridge: University Press, 2004. BRASIL. Lei 10.436, de 24 de abril de 2002. Poder Executivo, Brasília, DF, 24 abr. 2002. Disponível em: http://www.planalto.gov.br/ccivil_03/ leis/2002. Acesso em: 13 out. 2014.

BRASIL. Decreto № 5.626, de 22 de dezembro de 2005. Diário Oficial da União, Poder Executivo, Brasília, DF, 22 dez. 2005. Disponível em: http://www.planalto.gov.br/ccivil_03/_ato2004-2006/2005/decreto/ d5626.htm. Acesso em: 11 jun. 2018.

BRASIL. Decreto № 7.387, de 09 de dezembro de 2010. Diário Oficial da União, Poder Executivo, Brasília, DF, 27 jan. 2010. Disponível em: http://www.planalto.gov.br. Acesso em: 07 ago. 2015.

BRASIL. Nota técnica № 005 / 2011 / MEC / SEESP / GAB. Ministério da Educação, Secretaria de Educação Especial, Brasília, DF, 2011. Disponível em: http://portal.mec.gov.br/index.php?option=com_do- 
Libras, Bilinguismo e Educação Bilíngue: O Território do Surdo

Dayse Garcia Miranda

cman\&view=download\&alias=9959-nota-tecnica-05-2011-secadi\&Itemid=30192. Acesso em: 11 jun. 2018.

BRASIL. Lei № 13.005, de 25 de junho de 2014. Diário Oficial da União, Poder Executivo, Brasília, DF, 25 jun. 2014. Edição Extra, p. 1. Disponível em: http://www.planalto.gov.br/ccivil_03/_ato2011-2014/2014/lei/ 113005.htm. Acesso em: 11 jun. 2018.

BRASIL. Ministério da Educação. Plano Nacional de Educação 20142024. Brasília, 2014a . Disponível em: http//pne.mec.gov.br. Acesso em: 11 jun. 2018.

BRASIL. Relatório do Grupo de Trabalho, designado pelas Portarias № 1.060/2013 e № 91/2013, contendo subsídios para a Política Linguística de Educação Bilíngue - Língua Brasileira de Sinais e Língua Portuguesa. MEC/SECADI. Brasília, 2014b. Disponível em: http://www.bibliotecadigital.unicamp.br/document/?code=56513. Acesso em: 11 nov. 2018.

BRASIL. Lei n 13.146, de 06 de julho de 2015. Diário Oficial da União, Poder Executivo, Brasília, DF, 06 juL. 2015. Disponível em: http://www. planalto.gov.br/ccivil_03/_ato2011-2014/2014/lei/l13005.htm. Acesso em: 11 nov. 2018.

BRASIL. Decreto n 9.665, de 02 de janeiro de 2019. Diário Oficial da União, Poder Executivo, Brasília, DF, 02 jan. 2019. Disponível em: http:// www.planalto.gov.br/ccivil_03/_Ato2019-2022/2019/Decreto/D9665. htm. Acesso em: 15 fev. 2019.

FENEIS. Nota Oficial: Educação de Surdos na Meta 4 do PNE. 2013. Disponível em: http://blog.feneis.org.br/nota-meta-4-do-pne/. Acesso em: 11 jun. 2018.

FERNANDES, Eulália. Linguagem e surdez. Porto Alegre: Artmed, 2003. GROSJEAN, François. $\mathbf{O}$ direito da criança surda de crescer bilíngue. Universidade de Neuchâtel, Suíça: 2016, p. 1-5. GROSJEAN, François. Individual bilingualism. In: BRITO DE MELLO, Heloisa. The Encyclopedia of Language and Linguistics. Oxford: Pergamon Press, 2008, p. 163-176. 
Libras, Bilinguismo e Educação Bilíngue: O Território do Surdo

Dayse Garcia Miranda

HALLIDAY, Michael. El Lenguaje como Semiotica Social. México: Fondo de Cultura Economica, 1979.

PLAZA PUST, Carolina. Deaf education and bilingualism. In: PFAU, Roland.; STEINBACH, M.arkus; WOLL, Bencie. Sign Language: An International Handbook. Berlin: De Gruyter Mouton, 2012. p. 949-979. MIRANDA, Dayse. As mediações linguísticas do intérprete de língua de sinais na sala de aula inclusiva. Ano 2010, 178 f. Dissertação de Mestrado. Faculdade de Educação. UFMG, Belo Horizonte.

MIRANDA, Dayse. A multimodalidade no ensino de língua portuguesa como segunda língua para surdos: análise do uso do livro didático adaptado em Libras. Ano 2019, 276 f. Tese de Doutorado. Posling. CEFET-MG, Belo Horizonte.

OLIVEIRA. Gilvan. Declaração Universal dos Direitos Linguísticos: Novas Perspectivas em Política Linguística. Florianópolis: Mercado de Letras, 2003.

OLIVEIRA. Gilvan. Políticas Linguísticas como Políticas Públicas. In: GUADELUPE, T. B.; OURIQUES, N. D. Anuário Educativo Brasileiro: Visão Retrospectiva. São Paulo: Cortez, 2011.

QUADROS, Ronice; LILLO-MARTIN, Diane; PICHLER, Deborah. O que bilíngues bimodais têm a nos dizer sobre desenvolvimento bilíngue? In: Revista Letras de Hoje, Porto Alegre, v. 48, № 3, p. 380-388, 2013 QUADROS, Ronice; LILLO-MARTIN, Diane; PICHLER, Deborah. Libras. São Paulo: Parábola Editorial, 2019.

REFORMA POMBALINA (século XVIII). Disponível em: https://pt.wikipedia.org/wiki/Per\%C3\%ADodo_pombalino. Acesso em: 29 jun. 2020.

REVISTA EXAME - Disponível em: https://exame.abril.com.br/negocios/ dino/educacao-bilingue-cresce-em-todas-as-regioes-do-brasil-sht$\mathrm{ml}$. www.dino.com.br, rede de distribuição e divulgadora de notícias que garante a publicação dos conteúdos enviados por assessorias de imprensa ou diretamente por empresas em centenas de publishers. Acesso em: 11 nov. 2018.

SALGADO, Ana Claudia. Medidas de Bilingualidade: uma proposta. Ano 2008, 140f. Tese - PUC-Rio, Rio de Janeiro. 
Libras, Bilinguismo e Educação Bilíngue: O Território do Surdo

Dayse Garcia Miranda

SANTOS, Alessandra. Multilinguismo em Bonfim/RR: o ensino de Língua Portuguesa no contexto da diversidade linguística. 2012. 144 f. Tese - UNB, Brasília, 2012.

SILVA, Giseli. O bilinguismo dos surdos: acesso às línguas, usos e atitudes linguísticas. Revista Leitura, Maceió, v. 1, № 58, p. 124-144, Jan./Jun 2017a. ISSN 2317-9945

STURMER, Ingrid; THOMA, Adriana. Políticas educacionais e linguísticas para surdos: discursos que produzem a educação bilíngue no Brasil na atualidade. $37^{\text {a }}$ Reunião Nacional da ANPED. Florianópolis: UFSC. 2015. 